\title{
Integrated Environment I mpact Assessment of Brick Kiln using Environmental Performance Scores
}

\author{
Rajib Pokhrel and Heekwan Lee* \\ School of Urban and Environmental Engineering, Incheon National University 12-1 Songdo-Dong, Yeonsu-Gu, Incheon, Korea
}

*Corresponding author. Tel: +82-32-835-4689, E-mail: airgroup@incheon.ac.kr

\begin{abstract}
The capital city of Himalayan Country Nepal, Kathmandu Valley is surrounded by consecutive high mountains, which limits the air distribution and mixing effects significantly. It in turn generates steady air flow pattern over a year except in monsoon season. The air shed in the Valley is easily trapped by the surrounded mountains and the inversion layer formulated as the cap. The $\mathrm{PM}_{10}$ concentration was noticeably higher than the standard level $\left(120 \mu \mathrm{g} / \mathrm{m}^{3}\right)$ in urban and suburban area of Kathmandu valley for all seasons except monsoon period. The Valley area experiences similar wind patterns (W, WWS, and S) for a year but the Easterly wind prevails only during the monsoon period. There was low and calm wind blows during the winter season. Because of this air flow structure, the air emission from various sources is accumulated within the valley air, high level of air pollution is frequently recorded with other air polluted cities over the world. In this Valley area, brick kilns are recognized as the major air pollution source followed by vehicles. Mostly Bull Trench Kiln (BKT), Hoffman Kiln and Vertical Shaft Brick Kiln (VSBK) are in operation for brick firing in Kathmandu valley where the fuels such as crushed coal, saw dust, and natural gas are used for processing bricks in this study. Tool for the Reduction and Assessment of Chemical and Other Environmental Impacts (TRACl) was used for screening and quantifying the potential impacts of air emission from firing fuels. The total Environmental Performance Score (EPS) was estimated and the EPS of coal was approximately 2.5 times higher than those of natural gas and saw dust. It is concluded that the crushed coal has more negative impact to the environment and human health than other fuel sources. Concerning the human health and environment point of view, alternative environment friendly firing fuel need to be used for brick industry in the kiln and the air pollution control devices also need to be applied for minimizing the air emissions from the kilns.
\end{abstract}

Key words: Brick industry, Firing fuels, Air quality, TRACl, Environmental performance score

\section{INTRODUCTION}

Kathmandu valley, the capital city of Nepal is located between $27^{\circ} 32^{\prime} 13^{\prime \prime} \mathrm{N}$ to $27^{\circ} 49^{\prime} 10^{\prime \prime} \mathrm{N}$ latitude and $85^{\circ} 11^{\prime} 31^{\prime \prime} \mathrm{E}$ to $85^{\circ} 31^{\prime} 38^{\prime \prime} \mathrm{E}$ longitude. It lies between the Himalayas in the North and Mahabharata range in the South. The valley has a bowl shape topography and surrounded by a series of high mountain range above $2000 \mathrm{~m}$ altitude as in Fig. 1. The valley is situated at an average altitude of $1300 \mathrm{~m}$ above the sea level (Pudasainee et al., 2010; Tuladhar et al., 2002). During past three decades, the population of Kathmandu valley has increased drastically and the city has been expanded and densely urbanized. Annual population growth rate in the valley was above $4.5 \%$ while the nationwide population growth rate was approximately 2.5\% (Central Bureau of Statistics, Nepal, 2001). Therefore it has been a great challenge to maintain the clean environment including air quality issue in the Kathmandu Valley.

The air quality of the Valley was improved in 2003 and it was aggravated in 2005 again. There was a slight improvement on air quality in 2006 but it has been steadily worsening since 2007 (Chaudhari, 2010). Dust particles, oxides of nitrogen $\left(\mathrm{NO}_{\mathrm{x}}\right)$, carbon monoxide (CO), sulfur oxides ( $\mathrm{SO}_{\mathrm{x}}$ ), Hydrocarbons ( $\mathrm{HCs}$ ), benzenes, etc. are the major pollutants in the valley air (Panday et al., 2009). The increased exposure of $\mathrm{PM}_{10}$ is associated with various adverse health effect, such as respiratory diseases, cardiovascular mortality, morbidity and probably malignant lung diseases (Goldberg et al., 2006; Chang et al., 2005; Kan et al., 2003; Donaldson et al., 2001). Fine particulate matters are mostly generated from the vehicle emission and the secondary pollution aggravates the atmospheric visibility by scattering or absorbing the visible light (Pokhrel et al., 2011). Similarly, the gaseous pollutants in the air caus- 


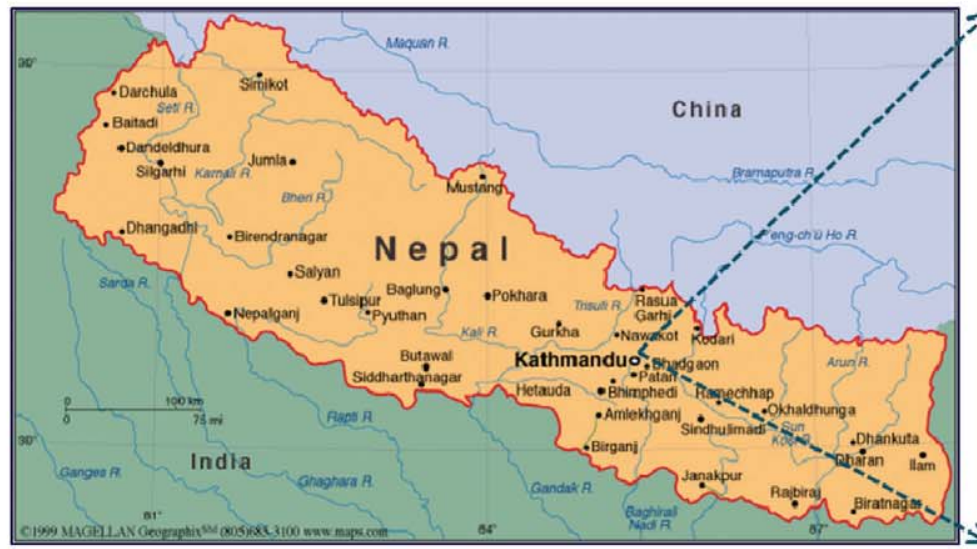

(a) Geographic location of Nepal

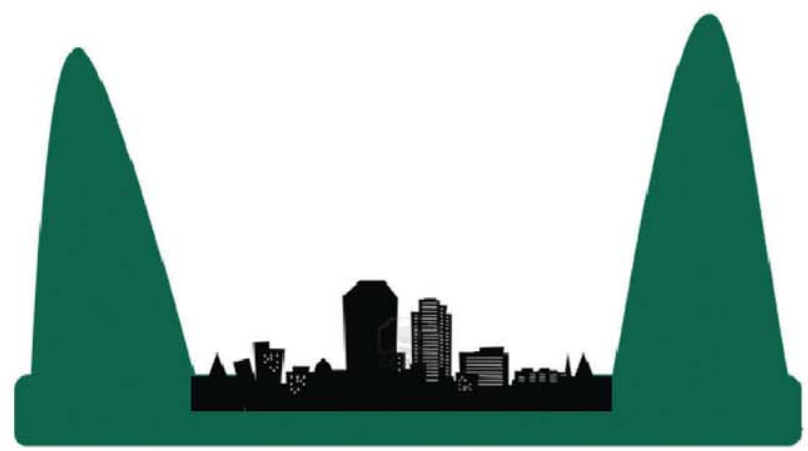

(c) Sectional view (X-X section of (b))

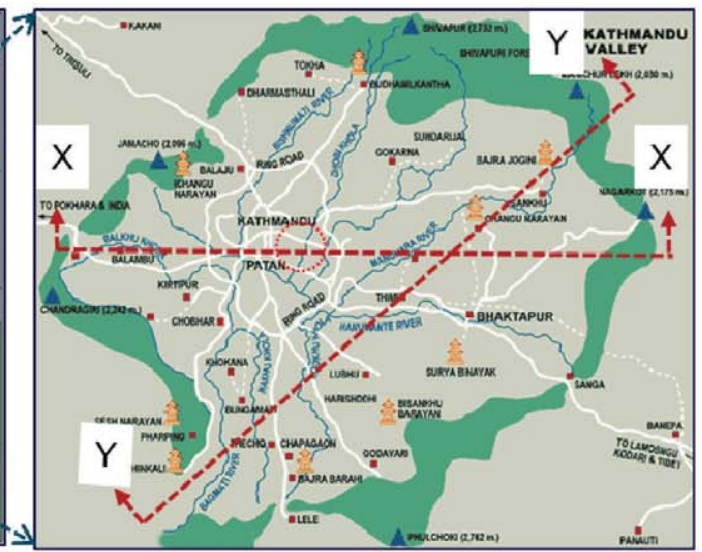

(b) Top view of Kathmandu Valley

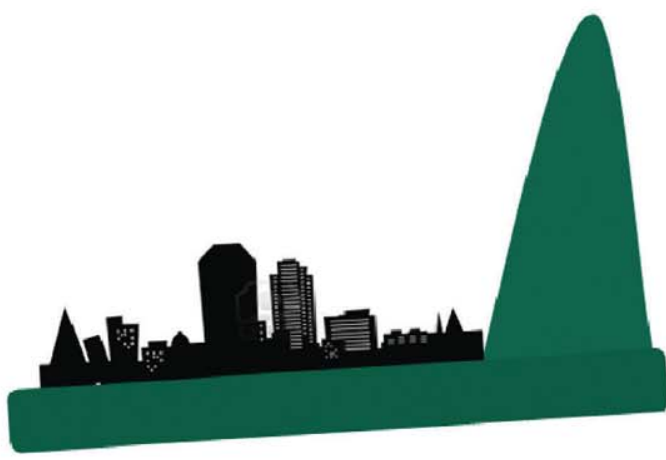

(d) Sectional view (Y-Y section of (b))

Fig. 1. Geographic position of Kathmandu Valley in Nepal.

es severe physical environmental and health effects (Panday et al., 2009). In addition, the inversion height is below the surrounding mountains and it plays a role like a lid for the Valley air mostly in the winter season when the air pollution is accumulated in the confined boundary and the air quality is aggravated in further (Pudasainee et al., 2010; Sapkota, 2002; Sharma, 1997).

Large number of vehicles, brick kiln factories, concrete gridding factories, etc. are the major sources of air pollution in Kathmandu valley. Brick kiln industry is one of the major air pollution sources where brick is one of major construction materials in the valley and its neighboring areas. The total production of 350 million bricks was the major single source of sulfur dioxide and suspended particulate matter in the valley. It contributes over $60 \%$ of emissions and responsible for the $31 \%$ of TSP (Total Suspended Particle) and 28 $\%$ of $\mathrm{PM}_{10}$ (Tuladhar et al., 2002; World Bank, 1997; Shrestha et al., 1996). Although it has a significant contribution to the valley air pollution, there is a lack of emission inventory data from each stage of brick production. Life Cycle Analysis (LCA) will be also applicable for characterizing the air emission from brick production in each stage and assessing the environmental impact. In this study, Tool for the Reduction and Assessment of Chemical and Other Environmental Impacts (TRACI) (Bare, 2002) was introduced to evaluate the environmental impacts by emissions from brick processing. In addition, optimized control techniques are also discussed for the improvement of air quality.

\subsection{Status of Brick Kiln Industries in Kathmandu, Nepal}

Brick manufacturing technology was introduced in Nepal in early 1950's and it was improved to Clamp Kiln and Bull Trench Kiln (BTK) for firing bricks. Crushed coal, fire wood, saw dust, etc. were used as firing fuel sources. Clamp kiln does not have chimnies but two movable metal chimneys of $16 \mathrm{~m}$ tall are usually installed in BTK. Both Clamp kiln and BTK are traditional, cheap and common technology for brick 


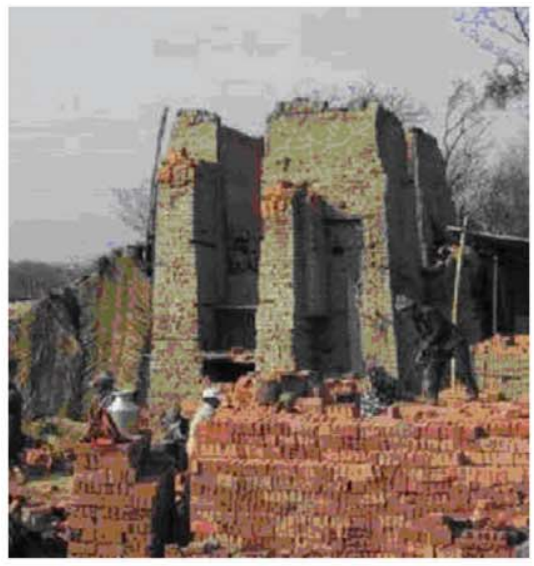

(a) Clamp Kiln

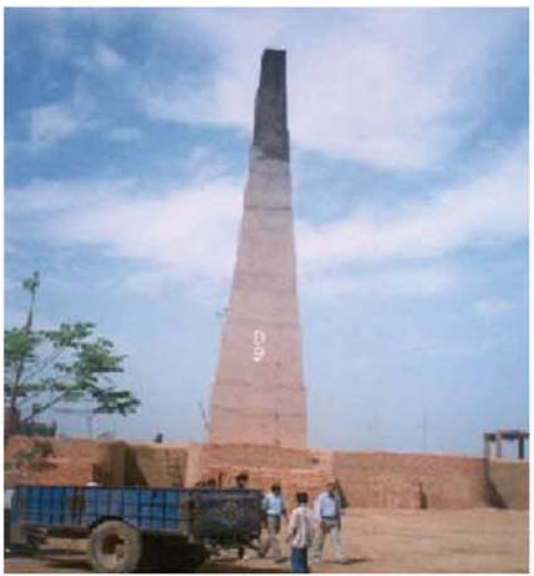

(c) Fixed chimney Kiln
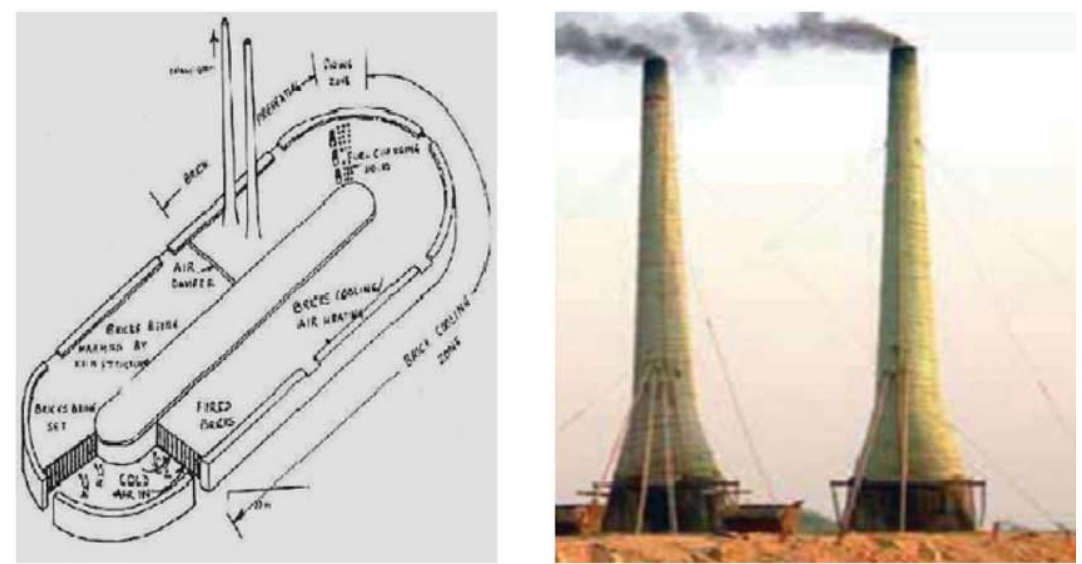

(b) Bull Trench Kiln (Movable chimney)

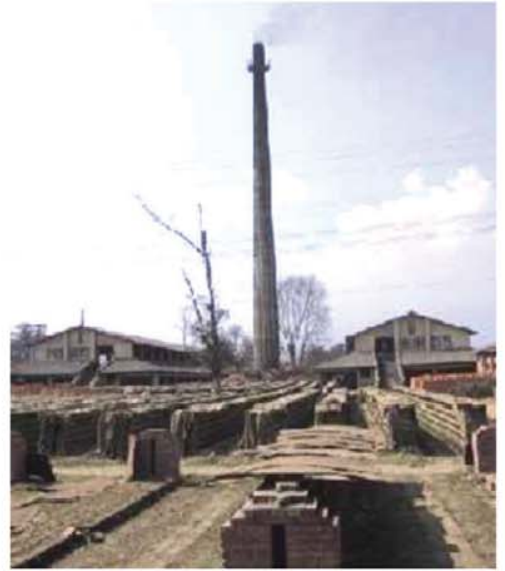

(d) Hoffman Kiln

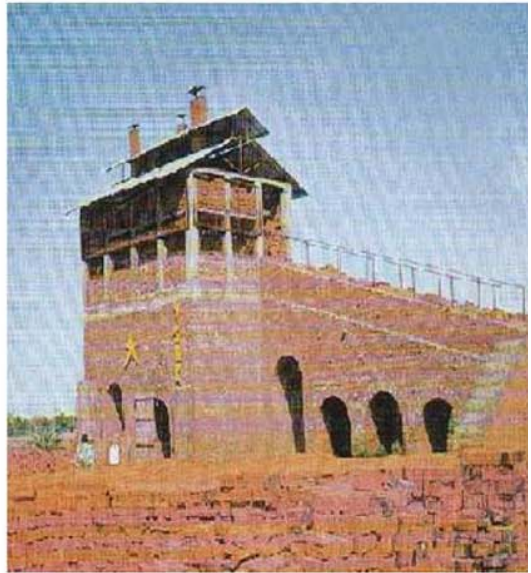

(e) Vertical Shaft Brick Kiln

Fig. 2. Schematic view of different types of Brick Kilns covering from traditional Clamp Kiln to improved VSBK used for firing bricks.

manufacturing and those have gradually been displaced by modern environmental friendly technology such as Hoffman and VSBK technologies. Hoffman brick kiln, developed by China was introduced into Nepal with the financial and technical assistance of China in 1970's. It has multiple chambers for loading green bricks from one side and offloading processed bricks from the other side (Tuladhar et al., 2002). Although the products has a high quality with bright feature and smooth surface, Hoffman technology could not compete with other existing technologies in Nepal due to the need of skilled manpower and high operating cost.

VSBK technology was also developed by China and it was introduced into Nepal as a technology transfer program. It was initially setup in 1992 and reinforced in 2003 and 2004. It is equipped with multiple vertical shafts with cross section $(1 \mathrm{~m} \times 1 \mathrm{~m})$ and height $6 \mathrm{~m}$. VSBK technology has gained the popularity within a short period in Nepal and neighboring countries due to the low operating cost and easy process as compare to Hoffman technology. In the same way, BTK technology was modified and recognized as Fixed Chimney Kiln (FCK). FCK was equipped with fixed chimney of height 130 feet and the gravitational settling chamber to settle down the particulate emissions. Fig. 2 and Table 1 summarizes different types of brick kilns for firing the bricks in Nepal and neighboring countries. It is reported that the modern technologies control the amount of air pollution and also consume less amount of fuel for firing same amount of brick (GIZ/NEEP, 2012; Tuladhar et al., 2002). The fuel consumption for firing bricks by Clamp Kiln, BKT and FCK were about 6,4 and 3 times higher respectively compare to VSBK technology. Concentration of suspended particulate matter (SPM) emissions from BKT and Fixed Chimney Kiln were about 14 times and 5 times higher 
Table 1. Summary of brick kilns operated and their categories in Nepal.

\begin{tabular}{|c|c|c|c|c|}
\hline \multirow{2}{*}{ Brick Kiln } & \multicolumn{3}{|c|}{ Chimney property } & \multirow{2}{*}{ Remarks } \\
\hline & Chimney type & Height & Number & \\
\hline Clamp Kiln & No chimney & $3-5 \mathrm{~m}$ & - & $\begin{array}{l}\text { - Production unit depends on size of kiln } \\
\text { - Takes } 12 \text { days to few weeks to complete firing }\end{array}$ \\
\hline BTK & Movable & $16-17 \mathrm{~m}$ & 2 & $\begin{array}{l}\text { - Production unit ranges from } 10,000-28,000 / \text { day } \\
\text { - Takes } 18-24 \text { days to complete firing }\end{array}$ \\
\hline FCK & Fixed & 130 feet $/ 39 \mathrm{~m}$ & 1 & $\begin{array}{l}\text { - Modified form of BTK and it is equipped with } \\
\text { gravitational settling chamber }\end{array}$ \\
\hline Hoffmann Kiln & Fixed & $30 \mathrm{~m}$ & 1 & $\begin{array}{l}\text { - } 51 \text { million piece/year in Kathmandu (CEN, 2002) } \\
\text { - Takes } 10 \text { days to complete brick firing }\end{array}$ \\
\hline VSBK & Fixed & $6 \mathrm{~m}$ & Multiple & $\begin{array}{l}\text { - Production unit ranges from } 3000-8000 / \text { shaft/day } \\
\text { - Takes } 24 \mathrm{hr} \text { to complete firing }\end{array}$ \\
\hline
\end{tabular}

respectively than VSBK technology. In addition, $\mathrm{CO}$, $\mathrm{HCs}, \mathrm{NOx}$ and $\mathrm{SO}_{2}$ were also emitted significantly higher from Clamp Kiln and BKT than Hoffman and VSBK (Tuladhar et al., 2002; Shrestha et al., 1997).

Although 125 brick kilns have been operating in valley, only 90 brick kilns were registered in the Department of Cottage and Small Industries in 2001 and the rest might be operated illegally. Clamp Kiln (9), Bull Trench Kiln (BKT) (113), Hoffmann Kiln (3), and Vertical Shaft (2) are in operation in the valley where they are recognized as one of the major pollution source (Chang et al., 2005; Tuladhar et al., 2002; ENPHO, 2001). Raw material composition, moisture content, kiln fuel types, kiln operation parameters, plant design, etc. are the major parameters which affect the air emission from the brick kiln. Local biomass, animal dungs, saw dust, coals, etc. are the major fuels for firing the bricks in the different types of brick kilns. This study mostly focuses on the air emission and the environmental impact during brick firing using different fuels such as saw dust, coal, natural gas, etc.

\section{METEOROLOGY AND AIR QUALITY OF VALLEY}

Ministry of Population and Environment of Nepal has established air pollution monitoring stations at six different locations. The six sampling sites include two heavy traffic urban area (traffic hotspot), one residential area (urban background), two semi-urban areas, and one rural area. The meteorological observation station has been set up at Tribhuvan International Airport (TIA). The meteorological data monitored at TIA produced a good agreement with the data monitored at other temporary stations, hence TIA data would be representative of the Kathmandu Valley (Panday et al., 2006; Regmi et al., 2003).
Wind speed and wind direction normally play a vital role for the dispersion of pollution. Air pollution settles down around the generation sources during the calm wind period, then it is transported to far neighboring area during the event of strong wind period. Windrose diagrams in Fig. 3 demonstrate the wind characteristics in the valley during different periods. Generally the valley experiences similar wind patterns (W, WWS, and S) for all period but the easterly wind prevails during the monsoon period. Strong wind speed above $7.0 \mathrm{~m} / \mathrm{s}$ is monitored during the pre-monsoon period and the low to calm wind speed is monitored in the winter season compared to other period (Aryal et al., 2008).

Ministry of Environment data shows that the absolute temperature of the valley varied from $2-17^{\circ} \mathrm{C}$ in the winter and $19-29^{\circ} \mathrm{C}$ in the summer. Fig. 4 demonstrates the $\mathrm{PM}_{10}$ concentration at different locations covering rural background area (Matyagaun), sub-urban area (Bhaktapur and Kirtipur), urban residential area (Thamel), and urban area (Putalisadak and Patan). $\mathrm{PM}_{10}$ concentration was significantly different in between urban and rural areas where $\mathrm{PM}_{10}$ the concentration was significantly higher than the standard level (120 $\left.\mu \mathrm{g} / \mathrm{m}^{3}\right)$ in the urban downtown and urban residential area for whole year except rainy season. Although Bhaktapur is regarded as a sub-urban area, the concentration of pollution level was remarkably high. The major cause of the high of air pollution concentration could be brick kilns in Bhaktapur area where a large numbers of brick kilns have been in operation. Bowl shape topography, lower temperature, and calm wind may cause the frequent temperature inversion in the valley, which traps the air pollutant inside the valley mostly in winter period, hence the pollution level during the winter season was found to be unfavorable (Panday et al., 2009b; Aryal et al., 2008; Panday et al., 2006). 


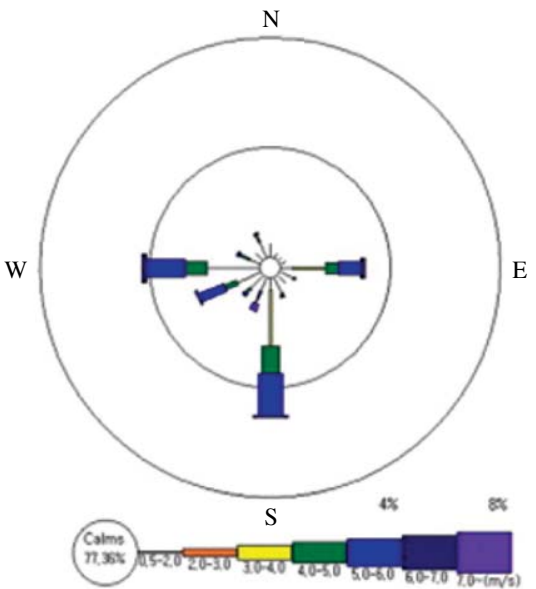

Monsoon

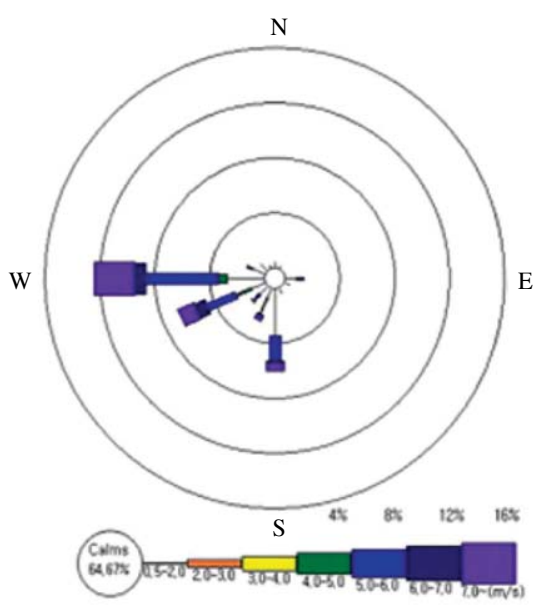

Pre-monsoon

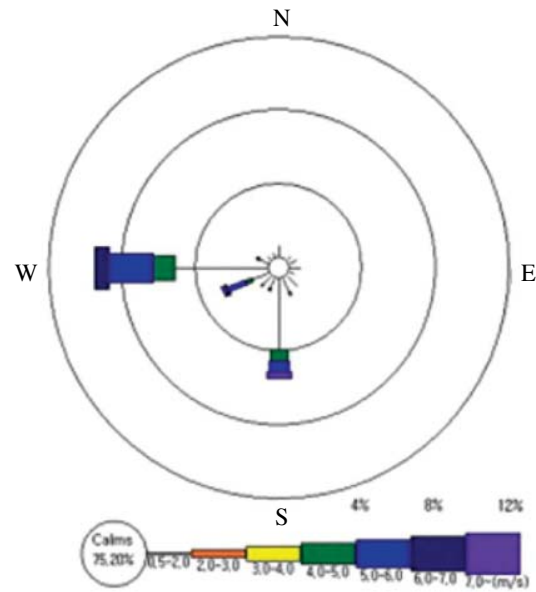

Post-monsoon

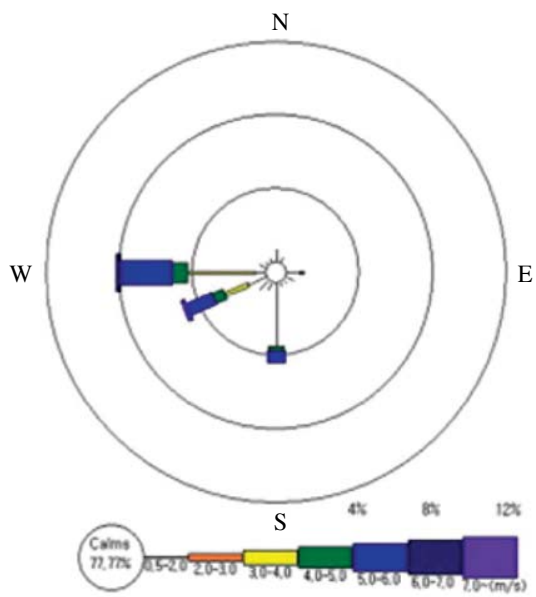

Winter

Fig. 3. Observed wind speeds and directions for four seasons in the Kathmandu Valley (Note, pre-monsoon; March-May, monsoon; June-September, post-monsoon: October-November, and winter: December-February) (Data source: Ministry of Environment - MOEST)).

\section{MODELING METHODS: Tool for the Reduction and Assessment of Chemical and Other Environmental Impacts (TRACI)}

TRACI tool intends to assist companies, federal facilities, industrial organizations, and public interest groups in performing board-based impact assessments of product on human health, environmental and resources depletion impacts. TRACI deals with the twelve common environmental impact categories such as ozone depletion, global warming, acidification, eutrophication, photochemical smog, human health cancer, human health noncancer, human health criteria, ecotoxicity, fossil fuel use, land use, and water use. TRACI does not work for the studies of accidental situations and it does not produce actual risk. It is simply a screening tool that allows the consideration and quantification of the potential of impacts (TRACI, 2002). The emissions data used in TRACI are Life Cycle Assessment (LCA) inventory data where LCA is a tool to measure the environmental consequence of product or process over its entire life. Generally, it begins with the resource consumption and ends with the residual return to the earth surface as in the flow chart in Fig. 4 (Ciambron, 1997; Vigon, 1994).

Environmental life-cycle assessment is a "cradle to grave" system approach for measuring environmental performance. The approach is based on the assumption that all stages in the life of a product generate environmental impacts and must be analyzed, including raw 


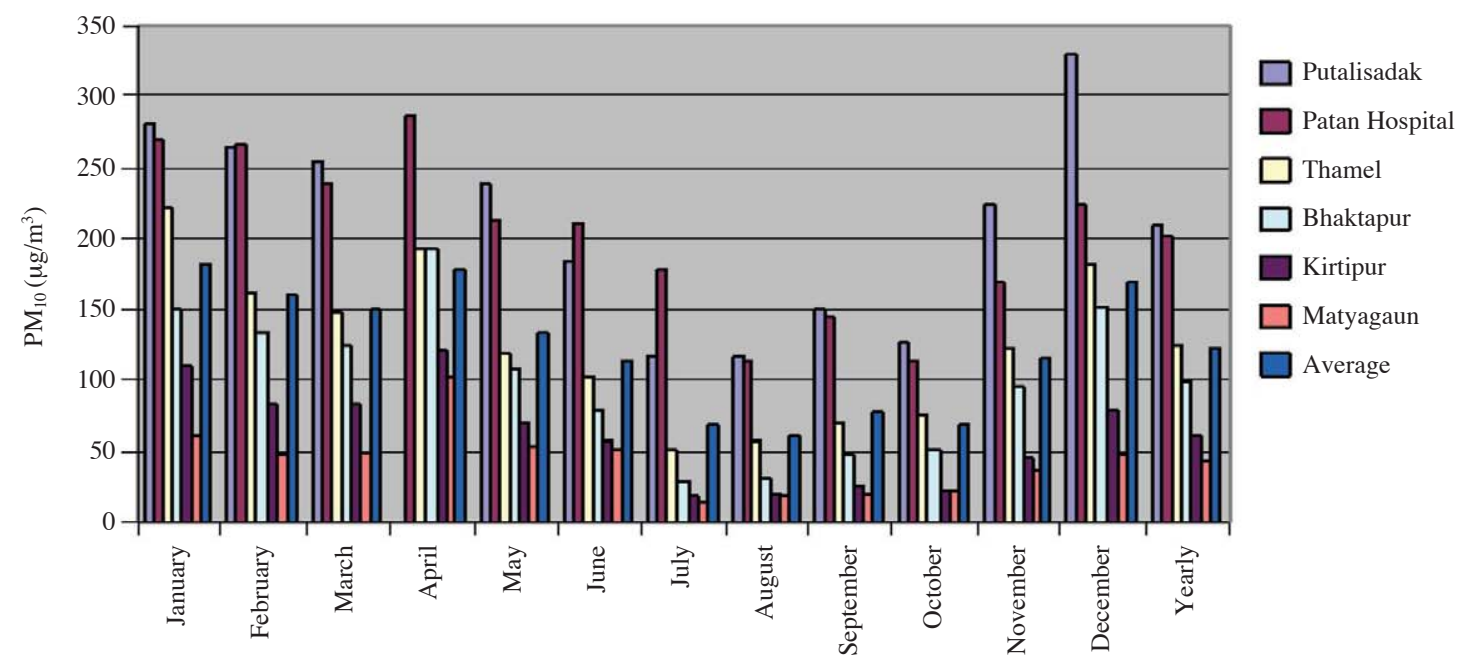

Fig. 4. Monthly average $\mathrm{PM}_{10}$ concentrations $\left(\mu \mathrm{g} / \mathrm{m}^{3}\right)$ at six monitoring sites for year 2005 (Data source: Ministry of Environment - 2005).

materials acquisition, product manufacture, transportation, installation, operation and maintenance, and ultimately recycling and waste management (Lippiatt, 2002). The types and amount of emissions vary in each production stages and it is controlled by the mixture of raw materials and product processing techniques. Fig. 5 demonstrates the process of brick production which begins from the raw material mining and ends with the disposal of unusable products. Burning zone of brick production is the most significant for air emission, hence authors focus on the emission from the burning zone and its respective impact on environment. Coal, saw dust and natural gas are common fuels for burning the bricks in the kiln as mentioned in the previous section.

Environmental impacts for each categories such as global warming $(\mathrm{GW})$, acidification, eutrofication, human health criteria (HH criteria), human health noncancer (HHNC), ozone depletion (OD), Smog, and ecotoxicity by different fuel types for each stages are calculated using the emission inventory data and impact assessment characterization factors. Equations 1-3 are the basic mathematics for computing environmental impact categories as well as total environmental performance score. Environmental impacts categories and impact assessment characterization factors for each categories are described in BEES 3.0 (Lippiatt, 2002). Normalization value and relative importance weight values for each impact categories are summarized in Table 3. Due to the lack of emission inventory data for each fuel type and kiln type in Nepal, the inventory data for different fuel types from each stages used in this model are referred from USEPA, AP-42, 11.3 as in Table 2.

$$
\begin{aligned}
& I A_{j k}=\sum_{i=1}^{n} I_{i j} \times I A \text { factor } \\
& \text { IA Score } \text { Sck }_{j k}=\frac{I A_{j k} \times I V w t_{k}}{\text { Norm }_{k}} \times 100 \\
& \text { Env Score }_{j}=\sum_{k=1}^{P} \text { IA Score }
\end{aligned}
$$

Where,

Env Score $_{j}=$ environmental performance score for the building product alternative $j$,

$P=$ number of environmental impact categories,

IA Score $_{j k}=$ characterized, normalized and weighted score for alternative " $j$ " with respect to environmental impact " $k$ ",

$I V w t_{k}=$ impact category importance weight for impact $k$,

$\mathrm{Norm}_{k}=$ normalization value for impact $k$,

$I=$ inventory flow,

$n=$ number of inventory flows in impact category $k$,

$I_{i j}=$ inventory flow quantity for alternative $j$ with respect to flow $I$,

IA factor $_{i}=$ impact assessment characterization factor for inventory flow $i$.

\section{MODELING RESULTS: Environmental Performance of Firing Fuels}

Three types of firing fuels such as coal, saw dust, and natural gas are considered and the environmental performances of the fuels are discussed by considering concerned environmental factors including global 

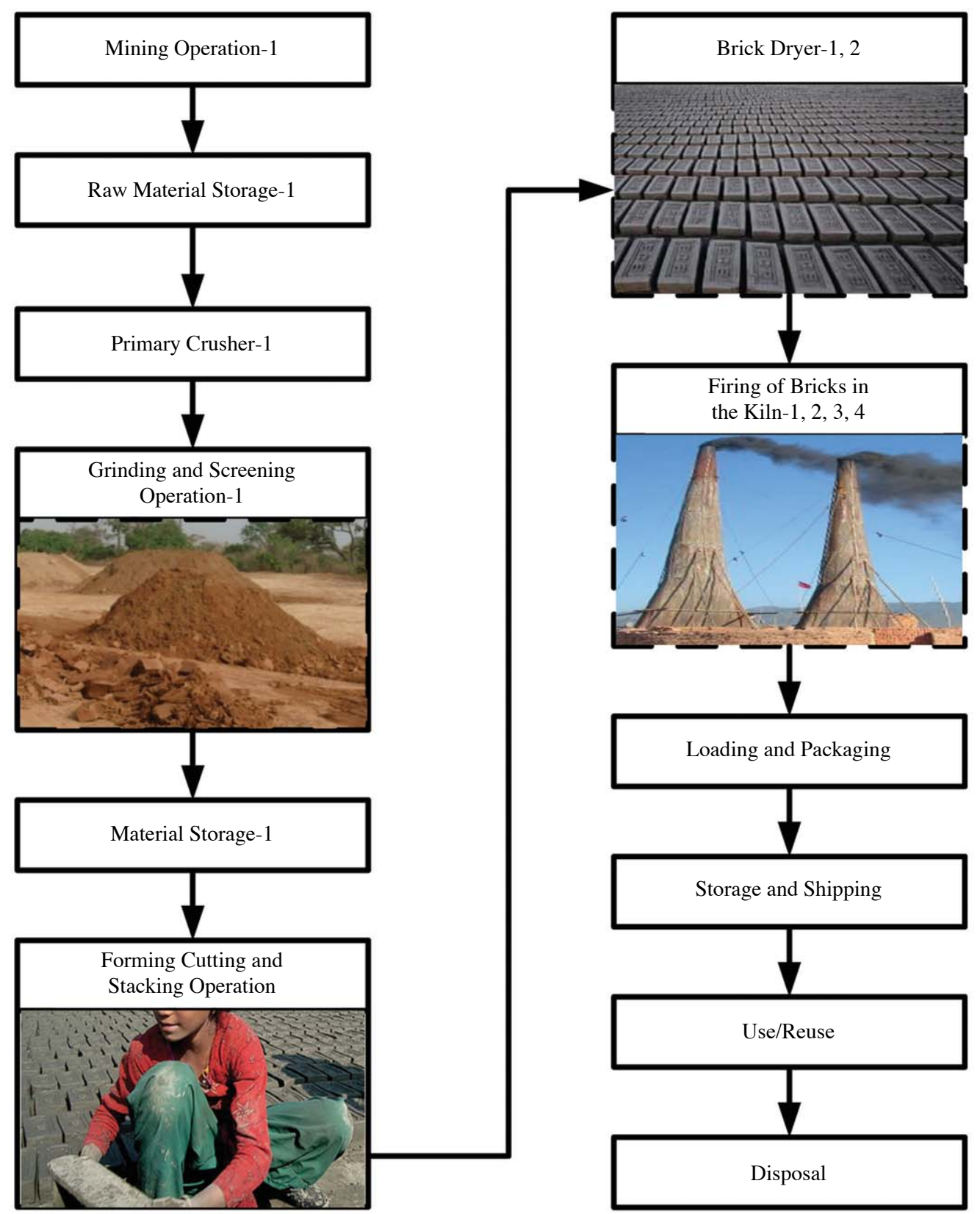

Fig. 5. Flow chart demonstrates the process of brick production. 1, 2, 3, 4 represent the PM, organic pollutants, gaseous emissions from fuel combustion and hydrogen fluoride emission, respectively.

Table 2. Summary of the inventory data of Particulates and Gases emissions from firing bricks using different fuel types.

\begin{tabular}{|c|c|c|c|c|c|c|c|}
\hline \multirow{2}{*}{ Fuel type } & \multirow{2}{*}{ Particulates } & \multirow{2}{*}{$\mathrm{SO}_{\mathrm{x}}$} & \multirow{2}{*}{$\mathrm{CO}$} & \multicolumn{2}{|c|}{ VOCs } & \multirow{2}{*}{$\mathrm{NO}_{\mathrm{x}}$} & \multirow{2}{*}{ Fluorides } \\
\hline & & & & Non-methane & $\overline{\mathrm{CH}_{4}}$ & & \\
\hline Coal & $0.34 \mathrm{~A}$ & $3.65 \mathrm{~S}$ & 0.71 & 0.005 & 0.003 & 0.73 & 0.5 \\
\hline Natural Gas & 0.012 & Negligible & 0.03 & 0.0015 & 0.003 & 0.09 & 0.5 \\
\hline Saw Dust & 0.12 & ND & ND & ND & ND & ND & ND \\
\hline
\end{tabular}

Note: Expressed as units per unit weight of brick produced, kilogram per megagram $(\mathrm{kg} / \mathrm{Mg})$. One brick weight about $2.95 \mathrm{~kg}$. ND=no data, $\mathrm{A}=\%$ of ash in coal, $\mathrm{S}=\%$ of sulfur in fuel. 


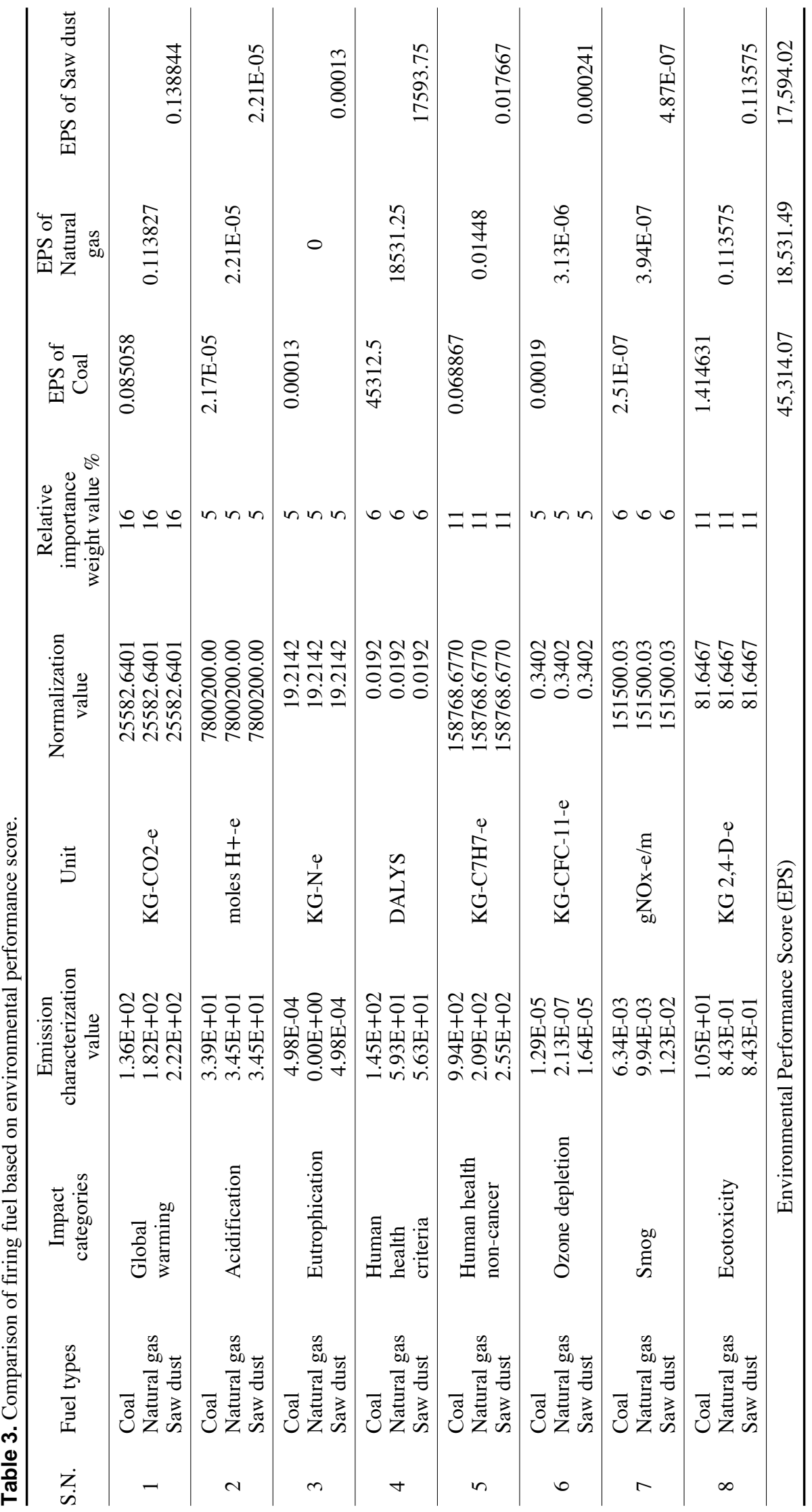


warming, acidification, eutrofication, human health criteria, human health non-cancer, ozone depletion, Smog, and ecotoxicity. The inventory data of USEPA for firing clay and brick products were used as a base data in TRACI. Although TRACI covers twelve environmental impact categories, eight environmental impact categories are included for analysis as in Table 3. Initially the emission characterization values were estimated and then normalized based on BEES 3.0 guideline (Lippiatt, 2002). Further the total environmental performance scores (EPS) of each fuel type was computed while EPS is a penalty score.

There was noticeable differences in the environmental performance scores for human health criteria among three fuels as shown in Table 3. It is mainly dependent on the amount of particulate matters, $\mathrm{NO}_{\mathrm{x}}$ and $\mathrm{SO}_{\mathrm{x}}$ in the air emission. The EPS of coal was about 2.5 times higher than both natural gas and saw dust for human health criteria. By analyzing the EPS scores, saw dust is found to be the worst for global warming, ozone depletion and photochemical smog but the EPS of coal is worst for human health criteria, human health noncancer and ecotoxicity. When dealing with the total environmental performance score, the EPS of coal was approximately 2.5 times higher than those of natural gas and saw dust.

According to the report published by Ministry of Environment, Nepal approximately 1,600 people were died and 18,000 were suffered respiratory disease in Kathmandu valley due to the valley air pollution (Chaudhari, 2010). In case of Nepal, coal is the major fuel for firing the bricks and brick kiln has been a major source of particulate and sulfur pollutants. There are two options for controlling particulate emissions from brick kilns, (a) by changing the fuel to natural gas or alternative environmental friendly fuel and (b) installing air pollution control technologies. If saw dust is used as major fuel, there would be deforestation and it cause further environmental and soil erosion problem in turn. In the meantime, natural gas is the alternative fuel but the country does not have the resource of natural gas and it needs to be imported from the neighboring country. Countries economy could not withstand the fuel cost and the manufacturing cost of brick would be boosted. Coal can also be used as firing fuel with some modification such as desulfurization and crushed coal, etc. Second part is installing of economic air pollution control technologies in the brick burning zone. Although many air pollution control techniques available in market, scrubber technique might be suitable for controlling particulate and sulfur emission from brick kilns based on economic, easy operation and maintenance. Excess water from scrubber can be reused for molding the bricks material that minimizes the water scarcity in the kiln area. The scrubber techniques have efficiency to reduce air pollutants $95 \%$ or more (Copper et al., 2002).

\section{CONCLUSIONS}

As described earlier, the Kathmandu Valley is surrounded by consecutive high mountains, which limits the air distribution and mixing effects significantly. It in turn generates steady air flow pattern over a year except in monsoon season. The air shed in the Valley is easily trapped by the surrounded mountains and the inversion layer formulated as the cap. Because of this air flow structure, the air emission from various sources is accumulated within the valley air. And the high level of air pollution is frequently recorded with other air polluted cities over the world. In the Valley air, the air emission from autobike is the primary source followed by the brick industries.

Nepal, building tradition is commonly adopted and constructed by using clay bricks which is made of soil mixture and burning afterwards. As it has been the major building material, the industry has also been growing steadily with increase of air emission. Subsequently it leads the impact of public health tremendously. The technology of brick kiln has been improved and upgraded so far, which reduces the air emission effectively but still requires further enhancement of energy efficiency and air emission level.

Currently crushed coal, saw dust, and natural gas are accessible and used for brick burning in the kilns. The brick kiln originated air emission was evaluated based on previously produced emission inventory data and analyzed using TRACI for scoring total environmental performance as a penalty mark. The EPS of coal was approximately 2.5 times higher than natural gas and saw dust. By considering the EPS score and public health, coal is found the worst firing fuel among three fuels. In addition, from human health and environmental point of view, alternative environmental friendly firing fuel need to be used for firing bricks in the kiln or the modification of existing fuels such as desulfurizing the coal, using the crushed coal in place of bulk crystal. In addition appropriate air pollution control device need to be installed for minimizing the emissions from the kiln by considering the economic value and available resources.

\section{ACKNOWLEDGEMENT}

This work was partially supported by the Incheon National University Research Grant 2012. Authors 
would also like to acknowledge the Ministry of Environment of Nepal for providing the required data.

\section{REFERENCES}

Aryal, R.K., Lee, B.K., Karki, R., Gurung, A., Kandasamy, J., Pathak, B.K., Sharma, S., Giri, N. (2008) Seasonal PM10 dynamics in Kathmandu Valley. Atmospheric Environment 42, 8623-8633.

Bare, J.C. (2002) Developing a Consistent Decision-Making Framework by Using the U.S. EPA's TRACI. http: //www.epa.gov/nrmrl/std/traci/aiche2002paper.pdf.

Chang, C.C., Tsai, S.S., Ho, S.C., Yang, C.Y. (2005) Air pollution and hospital admissions for cardiovascular diseases in Taipei. Taiwan, Environmental Research 98, 114-119.

Chaudhari, L. (2010) Onlinekhabar.com (http://www. onlinekhabar.com/wp/2010/04/06/55934.html).

Ciambrone, D.F. (1997) Environmental Life Cycle Analysis. Lewis Publisher, New York.

Copper, C.D., Alley, F.C. (2002) Air Pollution Control: A design approach. Waveland Press Inc., USA.

Donaldson, K., MacNee, W. (2001) Potential mechanism of adverse pulmonary and cardiovascular effects of particulate air pollution (PM10). International Journal of Hygienic and Environmental Health 203, 411-415.

ENPHO (2001) Status of brick kiln in Kathmandu valley. Environment and public health organization (ENPHO), Kathmandu.

GIZ/NEEP (2012) Baseline study of selected sector industries to access the potentials for more efficient use of energy.

Goldberg, M.S., Burnett, R.T., Yale, J.F., Valois, M.F., Brook, J.R. (2006) Association between ambient air pollution and daily mortality among persons with diabetes and cardiovascular disease. Environmental Research 100, 255-267.

Kan, H., Chen, C. (2003) Air pollution and daily mortality in Shanghai: a time-series study. Archives of Environmental Health 58, 360-367.

Lippiatt, B.C. (2002) Building for Environmental and Economic Sustainability Technical Manual and User Guide (BEES 3.0). USEPA, Office of pollution prevention and Toxics, NIST.

Panday, A.K., Prinn, R.G. (2009a), Diurnal cycle of air pollution in the Kathmandu Valley, Nepal: Observations. Journal of Geophysical Research 114, D09305.
Panday, A.K., Prinn, R.G., Schar, C. (2009b) Diurnal cycle of air pollution in the Kathmandu Valley, Nepal: 2. Modeling results. Journal of Geophysical Research 114, D21308, doi:10.1029/2008JD009808.

Pandey, A. (2006) The diurnal cycle of air pollution in the Kathmandu Valley, Nepal. Ph.D. thesis, Massachuetts Institute of Technology, US.

Pokhrel, R., Lee, H. (2011) Algorithm development of visibility monitoring using digital image analysis. Asian Journal of Atmospheric Environment 5-1, 8-20.

Pudasainee, D., Sapkota, B., Bhatnagar, A., Kim, S.H., Seo, Y.C. (2010) Influence of weekdays, weekends and bandhas on surface ozone in Kathmandu valley. Atmospheric Research, 95, pp. 150-156.

Regmi, R.P., Kitada, T., Kurata G. (2003) Numerical simulation of late wintertime local flows in Kathmandu Valley, Nepal:implication for air pollution transport. Journal of Applied Meteorology 42, 389-403.

Sapkota, B., Dhaubadel, R. (2002) Atmospheric turbidity over Kathmandu Valley. Atmospheric Environment 36, 1249-1257.

Sharma, C.K. (1997) Urban air quality of Kathmandu Valley "Kingdom of Nepal". Atmospheric Environment 31, 2877-2883.

Shrestha, R.M., Malla, S. (1996) Air pollution from energy use in developing country city - the case study of Kathmandu valley, Nepal. Clean Air Initiative (http:// cleanairinitiative.org/portal/system/files/articles-58928 _resource_1.pdf).

TRACI (2002) Tool for the Reduction and Assessment of Chemical and Other Environmental Impacts: User guide and system documentation. United States Environmental Protection Agency (USEPA), EPA/600/R02/052.

Tuladhar, B., Raut, A.K. (2002) Environmental and health impact of Kathmandu's brick kilns. Clean Energy Nepal (CEN).

Vigon, B.W., Tolle, D.A., Cornaby, B.W., Latham, H.C., Harrison, C.L., Boguski, T.L., Hunt, R.G., Sellers, J.D. (1994) Life-cycle assessment inventory guideline and principles. Lewis publisher, London.

World Bank (1997) URBAIR - Urban air quality management strategy in Asia: Kathmandu valley report, New York, USA.

(Received 28 July 2013, revised 25 February 2014, accepted 17 March 2014) 